\title{
Rapid Start-Up of Anammox by Immobilization and Its Response to Low Temperature Stress
}

\author{
Hong YANG ${ }^{1}$ and Xiaotong WANG \\ Key Laboratory of Beijing for Water Quality Science and Water Environmental \\ Recovery Engineering, College of Architectural Engineering, Beijing University of \\ Technology, Beijing 100124, China
}

\begin{abstract}
In view of the problems of slow start, easy loss and sensitive to low temperature environment in the suspension culture of anaerobic ammonia oxidation bacteria (AnAOB) suspension culture, polyvinyl alcohol (PVA) was used to prepare the anaerobic ammonia oxidation (anammox) immobilized filler, so as to realize the rapid start-up and activity improvement of anammox. Meanwhile, the response of nitrogen removal performance of encapsulated biomass to temperature reduction was determine by batch experiment. In addition, changes in the internal structure, flora composition and diversity of the filler were analyzed by scanning electron microscopy (SEM) and high-throughput sequencing. The results showed that the nitrogen removal capacity of the immobilized filler (E1) was significantly higher than that of the suspended sludge contrast system (S1) after 100d enrichment culture. The final nitrogen removal rate reached $1.168 \mathrm{~kg} \cdot(\mathrm{m} 3 \cdot \mathrm{d}-1)-1$, and the total nitrogen removal efficiency was $92 \%$. The immobilization improved the resistance of AnAOB to low temperature. At $15^{\circ} \mathrm{C}$, the effluent ammonia and nitrite of S1 were seriously accumulated, and E1 could maintain a stable nitrogen removal effect under the regulation of HRT. The population diversity was maintained in the immobilized filler, and the functional bacteria of anammox Candidatus Kuenenia was effectively enriched, accounting for $32.55 \%$ in E1. The results of this study provide valuable information for the application and popularization of anammox immobilized filler.
\end{abstract}

Keywords. Anaerobic ammonia oxidation (anammox), fast start-up, immobilized filler, low temperature, microbial community structure

\section{Introduction}

Anaerobic ammonium oxidation (anammox) refers to a biological process in which nitrite is used as electron acceptor to oxidize ammonia into nitrogen and produce a small amount of nitrate under the action of Anammox bacteria (AnAOB) [1]. Compared with the traditional nitrification and denitrification process, it does not need external organic carbon and aeration, and has the advantages of energy saving and cost reduction $[2,3]$.

However, the slow growth rate of AnAOB and its sensitivity to environmental conditions lead to a long start-up time of Anammox process. And in the process of operation is easy to occur bacteria loss, affecting the stability of the process. In particular,

${ }^{1}$ Corresponding Author, Hong YANG, Key Laboratory of Beijing for Water Quality Science and Water Environmental Recovery Engineering, College of Architectural Engineering, Beijing University of Technology, Beijing 100124, China; Email: yhong@bjut.edu.cn. 
low temperature limits the application of anammox process [4]. The low temperature environment not only slowed down the diffusion rate of the reaction matrix to cells, inhibited the growth of AnAOB, and led to the deterioration of the sedimentation performance and the erosion of the biomass, which resulted in the deterioration of the nitrogen removal performance. For example, when AnAOB is at the optimal temperature of $35^{\circ} \mathrm{C}$, the doubling time was $10-14$ days [5], while under the condition of $15^{\circ} \mathrm{C}$, the doubling time was 79 days [6]. Several studies have reported the failure of lowtemperature anammox $[7,8]$. Typical urban sewage temperature ranges from $10^{\circ} \mathrm{C}$ to $20^{\circ} \mathrm{C}$ and varies with the season, far below the optimal temperature range of AnAOB. Therefore, maintaining the amount of AnAOB in the reaction system while improving its resistance to low temperature, and maintaining the long-term effective operation of the anammox reaction system is the key to the current research.

Microbial immobilization technology has excellent performance in increasing cell density and maintaining biomass activity, and at the same time strengthens the resistance of microorganisms to toxic substances or adverse environmental conditions [9, 10], which is especially suitable for enrichment culture of slow-growing AnAOB. anammox immobilization technology has been extensively studied at home and abroad [9-11]. At present, polyvinyl alcohol-sodium alginate (PVA-SA) gel beads are generally used as immobilized carrier, but there are disadvantages such as difficulty in improving biological activity, insufficient mechanical strength and poor long-term operation stability $[12,13]$. In this study, PVA gel was mixed with newly active anammox sludge to prepare a new type of annular hollow skeletonless immobilized filler, in order to reduce biomass loss, stabilize the reaction environment, and realize rapid start of anammox and enrichment of AnAOB with less biomass. And through batch experiments, the response of immobilized fillers to cooling was investigated. In addition, scanning electron microscopy (SEM) and high-throughput sequencing technology were used to observe and analyze the changes in the internal structure and microbial community composition of the immobilized filler, in order to explore the method to realize the rapid start of anammox through entrapped $\mathrm{AnAOB}$, and to clarify the characteristics and advantages of anammox immobilized filler, so as to provide theoretical support for practical engineering application.

\section{Materials and Methods}

\subsection{Preparation of Anammox Encapsulation Biomass}

The inoculated sludge (MLSS: $9200 \mathrm{mg} \cdot \mathrm{L}^{-1}$, MLVSS/MLSS: $79.6 \%$ ) was obtained from a laboratory-scale anammox sequential batch bioreactor. The NRR was $0.55 \mathrm{~kg} \cdot\left(\mathrm{m}^{3} \cdot \mathrm{d}\right)^{-}$ ${ }^{1}$ and the nitrogen removal efficiency (NRE) of ammonia and nitrite were above $90 \%$. Collected anammox sludge and washed three times in the $\mathrm{KH}_{2} \mathrm{PO}_{3}$ buffer $(0.1 \mathrm{M} ; \mathrm{pH}$ 7.4) to remove substrate residue. Partially diluted sludge (MLSS: $6,035 \mathrm{mg} \cdot \mathrm{L}^{-1}$ ) was placed in a $0.5 \mathrm{~L}$ triangle flask for comparison. The other part of the sludge was used to prepare immobilized filler. The materials used to prepare the immobilized fillers included calcium carbonate $\left(\mathrm{CaCO}_{3}\right)$; powdered activated carbon (PAC, less than 120 mesh); trisodium phosphate $\left(\mathrm{Na}_{3} \mathrm{PO}_{4}\right)$; boric acid $\left(\mathrm{H}_{3} \mathrm{BO}_{3}\right)$ and PVA (degree of alcoholysis 20$99 \%$, degree of polymerization 2200). All the above materials were analytically pure grade.

The preparation method referred to the previous study [14]. Briefly, 20\% (w/w) PVA 
solution and anammox sludge, with a 95\% moisture content after centrifugation, were mixed. After mixing, the dry weight of the sludge accounted for $4 \%$ of the total mixture (MLSS: $\left.3050 \mathrm{mg} \cdot \mathrm{L}^{-1}\right)$. At the same time, $\mathrm{CaCO}_{3}\left(18.32 \mathrm{~g} \cdot \mathrm{L}^{-1}\right)$ and PAC $\left(38.30 \mathrm{~g} \cdot \mathrm{L}^{-1}\right)$ were added [15]. After that, the mixture was prepared in a hollow cylinder (the diameter was $1.0 \mathrm{~cm}$ and the thickness was $0.2 \mathrm{~cm}$ ) by extrusion equipment independently developed in the laboratory. After cross-linking in supersaturated $\mathrm{H}_{3} \mathrm{BO}_{3}$ solution, it was cut into small segments $\left(0.5 \mathrm{~cm}\right.$ in length). Then, it was soaked in $5 \% \mathrm{Na}_{3} \mathrm{PO}_{4}$ solution for $3 \mathrm{~h}$; the $\mathrm{pH}$ value was adjusted to $4-5$. Finally, the immobilized fillers E1 were obtained after washing with clean water.

\subsection{Feeding Media}

As shown in table 1, the main composition of inorganic synthetic wastewater mainly included $\left(\mathrm{mg} \cdot \mathrm{L}^{-1}\right): 0.6 \mathrm{NaHCO}_{3}, 0.025 \mathrm{KH}_{2} \mathrm{PO}_{4}, 0.15 \mathrm{CaCl}_{2} \cdot 2 \mathrm{H}_{2} \mathrm{O}, 0.3 \mathrm{MgSO}_{4} \cdot 7 \mathrm{H}_{2} \mathrm{O}$, $0.01 \mathrm{FeSO}_{4} \cdot 7 \mathrm{H}_{2} \mathrm{O}, 0.008 \mathrm{FeCl}_{3}$ and $1.00 \mathrm{~mL} \cdot \mathrm{L}^{-1}$ trace elements I and II [16].

Table 1. Compositions of inorganic wastewater.

\begin{tabular}{ll}
\hline Main ingredients & Concentration $\left(\mathbf{m g} \cdot \mathbf{L}^{-1}\right)$ \\
\hline $\mathrm{NH}_{4}\left(\mathrm{SO}_{4}\right)_{2}$ & $100-200$ \\
$\mathrm{NaNO}_{2}$ & $100-220$ \\
$\mathrm{KH}_{2} \mathrm{PO}_{4}$ & 25 \\
$\mathrm{MgSO}_{4} \cdot 7 \mathrm{H}_{2} \mathrm{O}$ & 300 \\
$\mathrm{NaHCO}_{3}$ & 600 \\
$\mathrm{CaCl}_{2} \cdot 2 \mathrm{H}_{2} \mathrm{O}$ & 150 \\
$\mathrm{FeCl}_{3}$ & 8 \\
$\mathrm{FeSO}_{4} \cdot 7 \mathrm{H}_{2} \mathrm{O}$ & 10 \\
$\mathrm{Trace}$ elements I & 1 \\
Trace elements II & 1 \\
\hline
\end{tabular}

\subsection{Experimental Methods}

\subsubsection{Activity Growth Experiment of Immobilized Filler}

Triangle flask with reaction volume of $0.5 \mathrm{~L}$ was used in the culture device. Part of the anammox encapsulated biomass was put into the reactor, and about $420 \mathrm{~mL}$ of inorganic synthetic wastewater was added to make the filling rate $20 \%$ (figure $1 \mathrm{a}$ ). The triangle flask was then placed in a $32^{\circ} \mathrm{C}$ constant temperature shaker at a controlled speed of 80 $\mathrm{r} \cdot \mathrm{min}^{-1}$ to ensure uniform material. Suspended sludge system (S1) was cultured synchronously under the same conditions (figure $1 b$ ).

The activity growth of the immobilized filler was divided into two stages. According to the efficiency growth, gradient increase of substrate concentration and shortener of hydraulic retention time (HRT) were successively adopted to increase the influent total nitrogen loading rate (NLR). The specific operation strategy was shown in table 2 . In the early stage of culture (0-20d), to avoid the inhibition of the anammox reaction by dissolved oxygen (DO), the DO concentration of the feed solution was reduced to $1.0 \mathrm{mg} \cdot \mathrm{L}^{-1}$ by the introduction of nitrogen of $99 \%$ purity before addition to the reactor. After (21-100d), the feed solution was configured with tap water without special 
deoxygenation. And dilute $\mathrm{H}_{2} \mathrm{SO}_{4}$ was used to adjust the influent $\mathrm{pH}$ of the reactor to $7.4 \pm 0.2$.
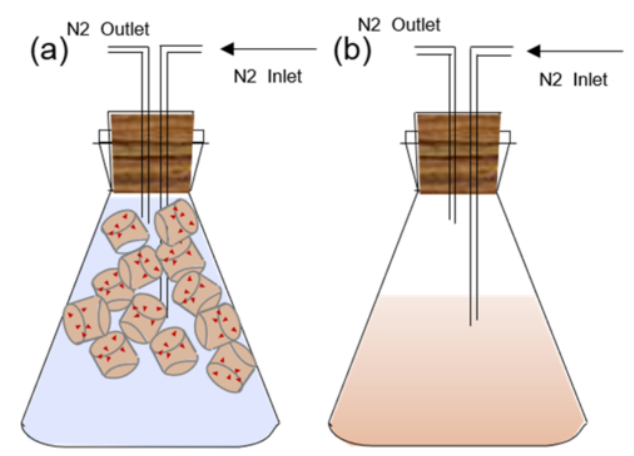

Figure 1. AnAOB culture device including: (a) immobilized filler system (b) suspended sludge control.

\subsubsection{Influence of Cooling on Properties of Immobilized Filler}

In order to study the nitrogen removal characteristics of immobilized fillers at low temperature, gradient cooling test was carried out after the culture stage. The experiment was divided into three phases, each with a temperature reduction of $5^{\circ} \mathrm{C}$, and run for 15 days (table 2). E1 and S1 were operated under the same conditions, and compared their nitrogen removal performance.

Table 2. Operation strategy of the anammox reactor.

\begin{tabular}{lllllll}
\hline Period & Time/d & Sample & HRT $(\mathbf{h})$ & Temperature $\left({ }^{\circ} \mathbf{C}\right)$ & $\mathbf{N H}_{4}{ }^{+}-\mathbf{N}\left(\mathbf{m g} \cdot \mathbf{L}^{-1}\right)$ & $\mathbf{N O}_{2}{ }^{-}-\mathbf{N}\left(\mathbf{m g} \cdot \mathbf{L}^{-1}\right)$ \\
\hline I & $1-60$ & E1, (S1) & 11 & $32 \pm 1$ & $100-200(150)$ & $100-220(165)$ \\
II & $61-100$ & E1, (S1) & 6 & $32 \pm 1$ & 150 & 165 \\
III & $101-115$ & E1, (S1) & 6 & 25 & 150 & $165(150)$ \\
IV & $116-130$ & E1, (S1) & $6(11)$ & 20 & 150 & $165(150)$ \\
V & $131-145$ & E1, (S1) & $11(22)$ & 15 & 150 & $165(150)$ \\
\hline
\end{tabular}

\subsection{Analytical Methods}

\subsubsection{Water Quality Analysis}

The amount of ammonia, nitrite, nitrite and MLSS was analyzed according to APHA standard methods [17]. The sum of ammonia, nitrite and nitrite was used to characterize total nitrogen (TN). su8020 scanning electron microscope was used in SEM (Hitachi, Japan), and reference was made for sample pretreatment [18].

\subsubsection{Sequencing and Bioinformatic Analysis}

Samples of inoculated sludge (S0), E1 after 100d culture (E1-100) and S1 after 100d culture (S1-100) were collected, and the microbial community structure of them was studied by using high-throughput Illumina Miseq sequencing platform (Illumina, San Diego, USA). Primers (341F: CCTACGGGNGGCWGCAG and 805R: GACTACHVGGGTATCTAATCC) were used for amplification and sequencing of the V3-V4 hypervariable region of the bacterial 16S rRNA gene. The bacterial 16S rRNA gene sequences were aligned using the National Center for Biotechnology Information 
(NCBI) database. The 16S rRNA genes of environmental microorganisms was carried out by using MEGAN software, and the operational taxonomic units (OTUs) were distinguished by clustering sequences at a threshold of $97 \%$. The diversity was calculated and analyzed according to the OTUs results, and the analysis results were visualized at last.

\section{Results and Discussion}

\subsection{Increased Activity of Immobilized Filler}

The nitrogen removal effect during the initiation and activity growth of $\mathrm{E} 1$ is shown in figure $2 \mathrm{a}$. In the first stage, with the gradient of influent load increasing, the effluent $\mathrm{NH}_{4}{ }^{+}-\mathrm{N}$ and $\mathrm{NO}_{2}{ }^{-}-\mathrm{N}$ showed a trend of gradual decrease, and the effluent $\mathrm{NO}_{3}{ }^{-}-\mathrm{N}$ increased stably, showing good anammox activity. At 61d, HRT was shortened to $6 \mathrm{~h}$. In order to stabilize the reaction, influent $\mathrm{NH}_{4}{ }^{+}-\mathrm{N}$ and $\mathrm{NO}_{2}{ }^{-}-\mathrm{N}$ concentrations were reduced to 150 and $165 \mathrm{mg} \cdot \mathrm{L}^{-1}$, respectively. At this stage, effluent nitrogen was also kept at a relatively low level, indicating the continuous improvement of E1 activity. However, the performance of S1 was not satisfactory. Although the effluent nitrogen concentration of S1 decreased gradually in the first 20 days, its nitrogen removal rate (NRR) increased slowly with the increase of influent load. Even after HRT was reduced to $6 \mathrm{~h}$, the effluent $\mathrm{NH}_{4}{ }^{+}-\mathrm{N}$ and $\mathrm{NO}_{2}{ }^{-}-\mathrm{N}$ accumulated and stabilized at about $70 \mathrm{mg} \cdot \mathrm{L}^{-1}$. This indicated that $\mathrm{S} 1$ cannot adapt to the rapid increase of NLR, leading to the deterioration of its effluent water quality. The reasons are as follows: on the one hand, the suspended sludge system inevitably has biomass loss and slow growth of AnAOB, leading to a long start-up period. On the other hand, after 20 days, the water was supplied with tap water without deoxygenation $(\mathrm{DO}=4-6 \mathrm{mg} / \mathrm{L})$, which interfered with the low activity of AnAOB [19].

NRR and NRE curves more clearly reflected the difference in nitrogen removal ability between E1 and S1 (figure 2c). The NRR of E1 increased rapidly, and the nitrogen removal ability of E1 was obviously better than that of S1. Although the inoculation sludge concentration of S1 was twice that of E1, the NRR of E1 finally reached 1.2 $\mathrm{kg} \cdot\left(\mathrm{m}^{3} \cdot \mathrm{d}\right)^{-1}$, which was twice that of $\mathrm{S} 1$, and the NRE was stabilized at more than $90 \%$. Ali et al. [20] reported similar results that the start-up speed of the column reactor containing immobilized biomass of $0.33 \mathrm{~g} \cdot \mathrm{VSS}^{-1}$ was significantly faster than that of the reactor containing granular sludge of $2.5 \mathrm{~g} \cdot \mathrm{VSS}^{-1}$. It can be seen that by encapsulating AnAOB, E1 can realize rapid start of anammox and effective removal of TN with less biomass. This is very meaningful for AnAOB with a long doubling time.

Further analysis of the nitrogen removal ratio is shown in figure $2 \mathrm{~d}$. The mean value of $\triangle \mathrm{NO}_{2}{ }^{-}-\mathrm{N} / \triangle \mathrm{NH}_{4}{ }^{+}-\mathrm{N}$ of E1 was 1.162 , higher than that of $\mathrm{S} 1$, while the mean value of $\triangle \mathrm{NO}_{2}{ }^{-}-\mathrm{N} / \triangle \mathrm{NH}_{4}{ }^{+}-\mathrm{N}$ of E1 was 1.159 , lower than that of $\mathrm{S} 1,1.17$. Therefore, higher $\mathrm{NO}_{2}{ }^{-}-\mathrm{N}$ removal and less $\mathrm{NO}_{3}{ }^{-}-\mathrm{N}$ generation in E1 enhanced its NRE. However, the nitrogen removal ratio of $\mathrm{E} 1$ and $\mathrm{S} 1$ was lower than the theoretical ratio of anammox reaction. This means that under the premise of anammox as the main reaction, there were nitrification, denitrification and other bacteria that participate in the nitrogen cycle to synergistically remove nitrogen. Similar reports have been reported in previous studies. For example, Tao et al. [21] found that the average value of $\triangle \mathrm{NO}_{2}{ }^{-}-\mathrm{N} / \triangle \mathrm{NH}_{4}{ }^{+}-\mathrm{N}$ was 1.45 and the average value of $\triangle \mathrm{NO}_{3}{ }^{-}-\mathrm{N} / \triangle \mathrm{NH}_{4}{ }^{+}-\mathrm{N}$ was 0.21 when they started the biofilter with anammox immobilized filler. Chen et al. [22] found that the reaction 
measurement ratio $\triangle \mathrm{NO}_{2}{ }^{-}-\mathrm{N}: \triangle \mathrm{NH}_{4}{ }^{+}-\mathrm{N}: \triangle \mathrm{NO}_{3}{ }^{-}-\mathrm{N}$ was $1: 1.11: 0.28$ in the study of matrix dynamics of anammox immobilized beads, which was discrepant with the theoretical ratio of 1:1.32:0.26. This was related to the difference of inoculation sludge and culture conditions. In this study, the widespread denitrification resulted in a low concentration of $\mathrm{NO}_{3}{ }^{-}-\mathrm{N}$ in the effluent of $\mathrm{E} 1$ and $\mathrm{S} 1$. In addition, the favorable microenvironment in the immobilized carrier weakened the interference of DO and inhibited the activity of nitrite oxidizing bacteria (NOB) in E1. In S1, NOB used DO to convert $\mathrm{NO}_{2}{ }^{-}-\mathrm{N}$ to $\mathrm{NO}_{3}{ }^{-}-\mathrm{N}$, resulting in its $\triangle \mathrm{NO}_{3}{ }^{-}-\mathrm{N}$ higher than that of $\mathrm{E} 1$.
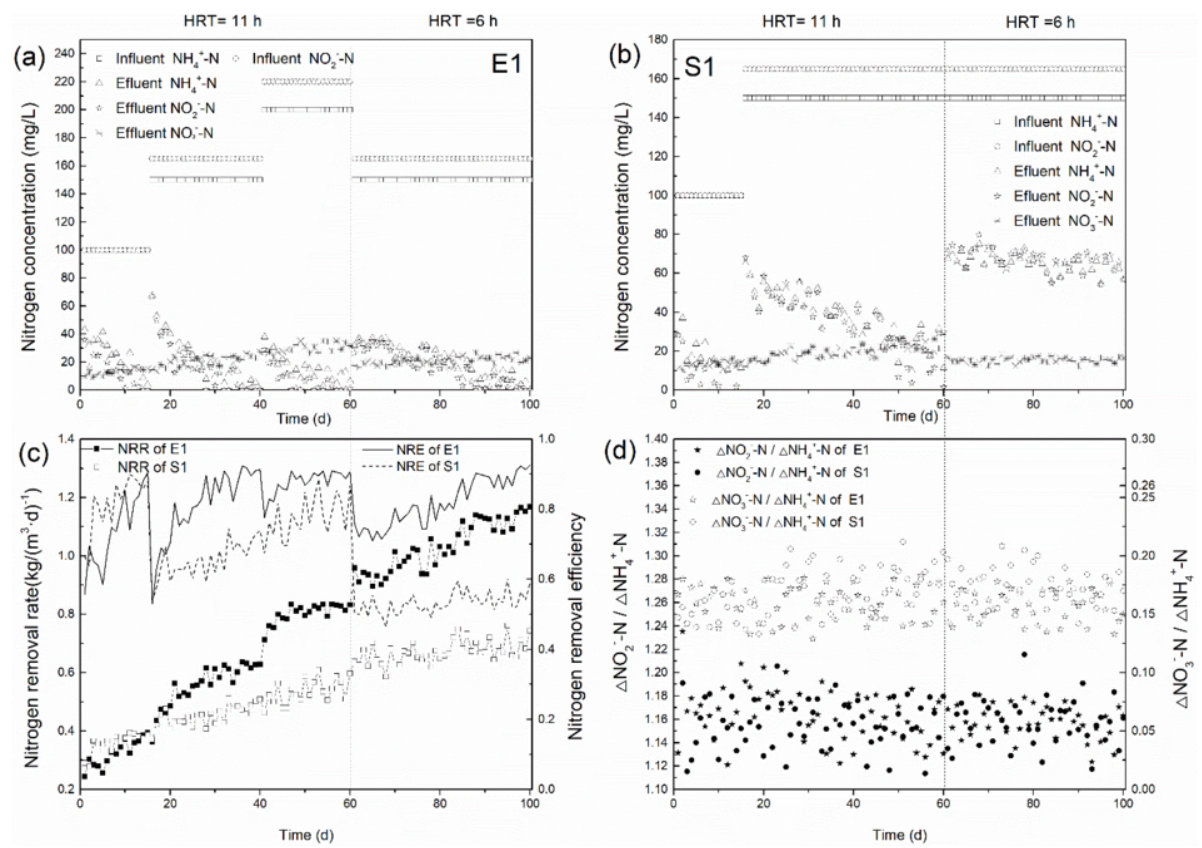

Figure 2. The improvement of nitrogen removal performance includes: (a) influent and effluent nitrogen concentrations of E1; (b) influent and effluent nitrogen concentrations of S1; (C) NRR and NRE; and (D) stoichiometric ratio of nitrogen removal.

In summary, the fast start of anammox can be achieved through immobilization. Compared with suspension culture, the stable microenvironment in the immobilized carrier is more conducive to the improvement of AnAOB activity.

\subsection{Morphology And Structure of Immobilized Carrier}

Figure 3 shows the physical image of E1 and the internal structure of the immobilized filler observed by SEM on the 100th day. Compared with the previously reported PVA gel beads, the hollow immobilized filler structure used in this study enhanced mass transfer.

Figures $3 b$ and $3 c$ clearly showed that there were abundant voids and skeleton structures for bacteria attachment and growth in E1, which provide good conditions for matrix transfer and cell growth. The surface was like a crater, and AnAOB with a diameter of $0.8-1.2 \mu \mathrm{m}$ grew around the pore in the form of a load. It can be seen that AnAOB was enriched in the immobilized carrier, which supports the good nitrogen 
removal performance of $\mathrm{E} 1$.

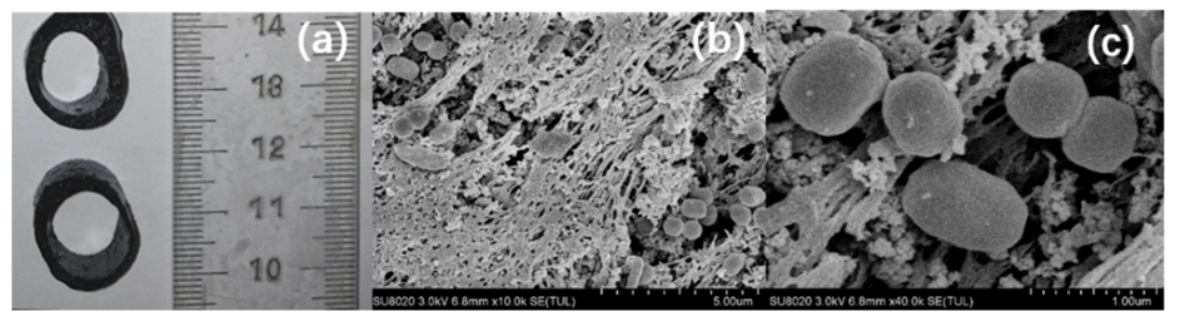

Figure 3. Physical image of immobilized filler (a) SEM images including: (b) internal $\times 10 \mathrm{~K}$ and (c) internal $\times 40 \mathrm{~K}$.

\subsection{Response of Immobilized Filler to Temperature Decrease}

The response of the immobilized filler to a temperature gradient drop was investigated through a batch test (figure 4). As can be seen from figure $4 \mathrm{a}$, when the temperature was reduced from $32^{\circ} \mathrm{C}$ to $25^{\circ} \mathrm{C}$, the NRE was basically not affected, and the effluent nitrogen concentration remained at a relatively low level. When the temperature continues to drop to $20^{\circ} \mathrm{C}$, the effluent $\mathrm{NH}_{4}{ }^{+}-\mathrm{N}$ and $\mathrm{NO}_{2}{ }^{-}-\mathrm{N}$ increase and stabilize to about $60 \mathrm{mg} \cdot \mathrm{L}^{-1}$. It can be seen that $20^{\circ} \mathrm{C}$ had a negative effect on the activity of $\mathrm{E} 1$, but it did not continue to deteriorate. Then the temperature was lowered to $15^{\circ} \mathrm{C}$. In order to avoid the damage of high concentration substrate to AnAOB, the HRT was extended to $11 \mathrm{~h}$. At this stage, the effluent nitrogen concentration returned to a lower level similar to that at $25^{\circ} \mathrm{C}$. This indicated that the activity of anammox immobilized filler was elastic at low temperature, and the extension of HRT could alleviate the adverse effects of low temperature on the activity of anammox.

Figure $4 \mathrm{~b}$ showed that $\mathrm{S} 1$ has poor resistance to temperature drop. At $25^{\circ} \mathrm{C}$, the effluent $\mathrm{NH}_{4}{ }^{+}-\mathrm{N}$ and $\mathrm{NO}_{2}{ }^{-}-\mathrm{N}$ reached $70 \mathrm{mg} \cdot \mathrm{L}^{-1}$, and the fluctuation increased to $80 \mathrm{mg} \cdot \mathrm{L}^{-1}$, which was significantly higher than that of E1. Similarly, in order to avoid the inhibition of substrate accumulation on AnAOB, HRT was extended to $11 \mathrm{~h}$ at $20^{\circ} \mathrm{C}$. However, this did not effectively alleviate the effect of low temperature on the activity of S1, and the effluent nitrogen concentration continued to rise to more than $90 \mathrm{mg} \cdot \mathrm{L}^{-1}$. Therefore, the HRT had to be extended to $22 \mathrm{~h}$ at $15^{\circ} \mathrm{C}$. Although the extension of HRT temporarily alleviated the inhibition of low temperature on the activity of anammox, that is, the effluent $\mathrm{NH}_{4}{ }^{+}-\mathrm{N}$ and $\mathrm{NO}_{2}{ }^{-}-\mathrm{N}$ concentrations decreased to about $30 \mathrm{mg} \cdot \mathrm{L}^{-1}$ from day 131 to day 137 . Unfortunately, with the extension of operation time, the effluent nitrogen concentration showed an increasing trend again. It can be seen that low temperature increased the instability of the suspended sludge system. 

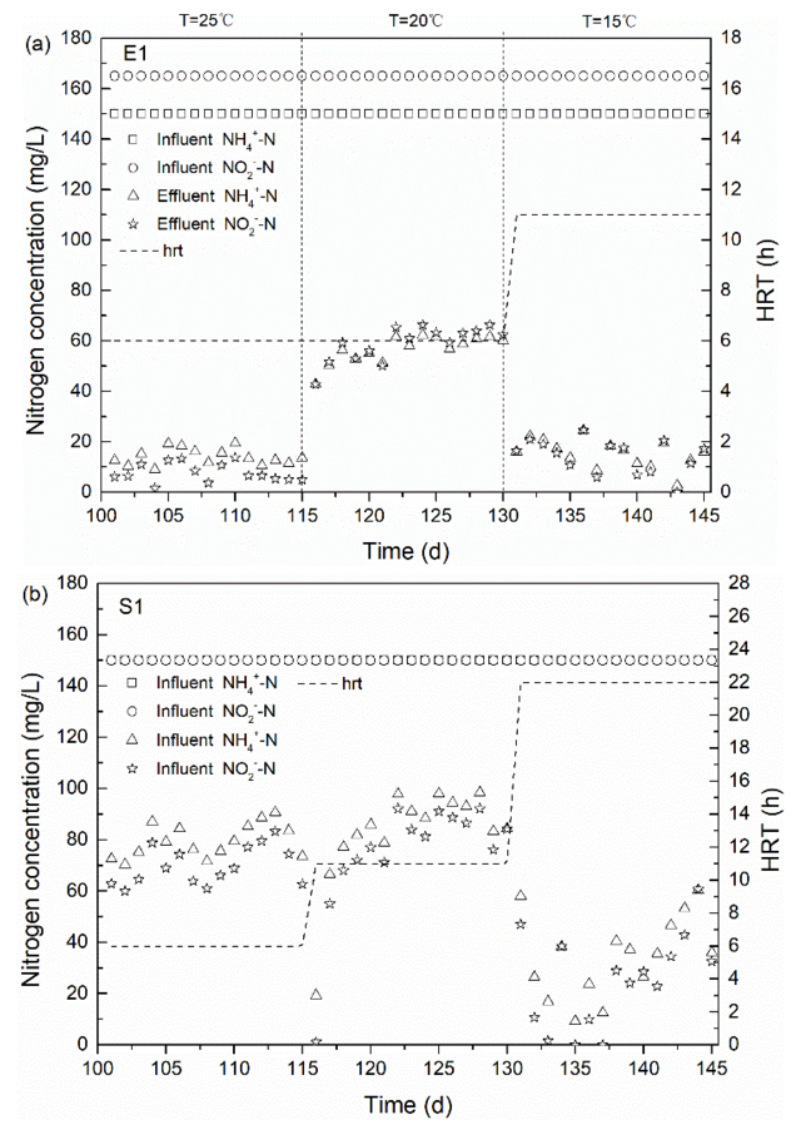

Figure 4. Effects of gradient cooling on anammox activity including (a) E1 and (b) S1.

\subsection{Analysis of Bacterial Diversity}

The flora structure and diversity of E1 and S1 before and after culture were studied by high-throughput sequencing technology. Table 3 lists the number and diversity index of sample OTUs. A total of 208,719 effective sequences were generated from the three DNA samples, which were divided into 8526 OTUs. After 100 days of operation, the Simpson index of E1 and S1 increased to 0.12 and 0.06 , respectively. These results indicated that the community diversity of E1 was lower than that of S1, and E1 had a more specific flora composition. At the same time, ACE index of E1 was higher than that of S1, indicating that E1 had more abundant flora composition than S1, that is, the stable microenvironment in the immobilized filler promoted the growth and enrichment of functional bacteria.

Table 3. Diversity index changes of samples in different periods.

\begin{tabular}{llllll}
\hline Sample & Seq num & OTU num & ACE index & Chao1 index & Simpson \\
\hline S0 & 62752 & 2866 & 44075.09 & 20105.93 & 0.05 \\
E1-100 & 60612 & 1938 & 25220.11 & 11434.53 & 0.12 \\
S1-100 & 85355 & 3722 & 17886.00 & 12767.02 & 0.06 \\
\hline
\end{tabular}


Figure 5 showed the changes in the composition of E1 and S1 flora before and after culture. Figure $5 \mathrm{a}$ listed the phyla with the relative abundance of microbial community $\geq 1 \%$, which belonged to Planctomycetes; Proteobacteria; Actinobacteria; Firmicutes; Chloroflexi; Bacteroidetes and other 12 phyla. However, before and after operation, the relative abundance of each phylum changed. For example, Proteobacteria decreased from $57.18 \%$ to $40.05 \%$ and $42.71 \%$, respectively, but still accounted for the largest proportion of the whole microbial system, which was consistent with the distribution of bacterial communities in most anammox reactors [23]. The second was Planctomycetes belonging to AnAOB, whose proportion increased from $12.8 \%$ to $33.13 \%$ (E1) and $17.7 \%$ (S1), respectively. This result verified the good nitrogen removal performance of E1, and verified from the perspective of microorganisms that the immobilized filler was more conducive to AnAOB enrichment than the suspended sludge system.
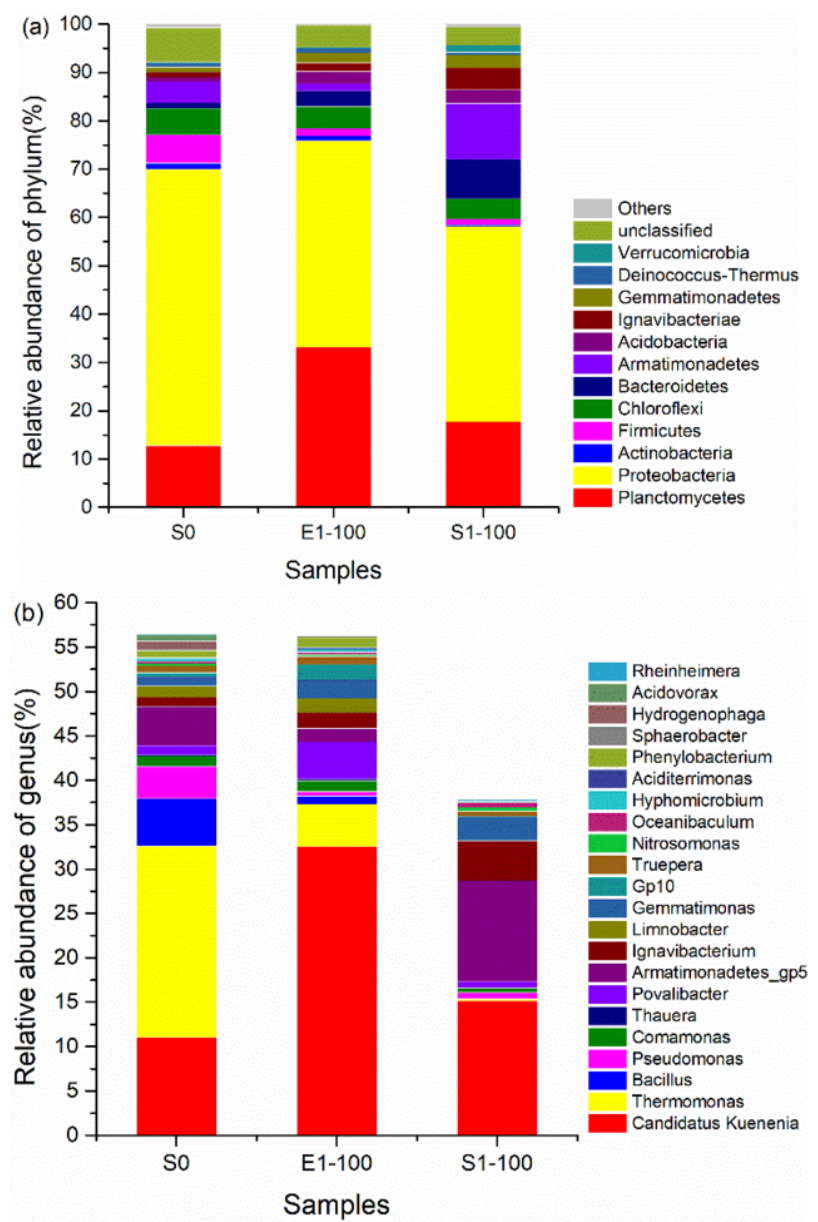

Figure 5. Relative percentage of the community composition of sample.

At the genus level (figure 5b), Thermomonas was transformed from dominant bacteria to Candidatus Kuenenia, with a relative abundance of $32.55 \%$ in E1. Thermomonas is a group of denitrifying bacteria, and Candidatus Kuenenia is a 
functional anammox bacterium. This means that AnAOB was a dominant species in this system. The Bacillus and Pseudomonas with denitrification function were decreased [24], while Povalibacter and Armatimonadetes_gp5 increased slightly in E1 and S1, respectively, indicating that a small number of heterotrophic bacteria inevitably coexisted in the anammox system to eliminate metabolites for AnAOB. Because AnAOB could not be isolated and purified, E1 could not only increase the proportion of AnAOB, but also better maintain the diversity of anammox associated flora, which could help to maintain the balance of microenvironment in the immobilized carrier.

In addition, a small amount of Nitrosomonas was found in S0, E1 and S1 (0.26; 0.23; 0.42), which oxidized $\mathrm{NH}_{4}{ }^{+}-\mathrm{N}$ to $\mathrm{NO}_{2}{ }^{-}-\mathrm{N}$, explaining why the conversion ratio of the reaction system $\Delta \mathrm{NO}_{2}{ }^{-}-\mathrm{N} / \Delta \mathrm{NH}_{4}{ }^{+}-\mathrm{N}$ was less than the theoretical ratio of anammox reaction of 1.32 .

\section{Conclusion}

- Immobilized filler improved the resistance of AnAOB to low temperature, and $25^{\circ} \mathrm{C}$ had no effect on E1 nitrogen removal performance. At $15^{\circ} \mathrm{C}$, E1 could maintain stable NRE by appropriately extending HRT.

- High-throughput sequencing analysis showed that E1 formed a specific and stable bacterial community structure, and the population diversity was maintained. anammox functional bacterium Candidatus Kuenenia was effectively enriched in the filler, accounting for $32.55 \%$, which was 2.15 times that of the suspended sludge.

- Rapid start of anammox reaction was achieved by encapsulating anammox biomass. The nitrogen removal performance of the immobilized carrier was better than that of the suspended sludge system. On the 100th day, the NRR of immobilized filler reached $1.168 \mathrm{~kg} \cdot\left(\mathrm{m}^{3} \cdot \mathrm{d}^{-1}\right)$, and the NRE was $92 \%$.

\section{Acknowledgments}

This research was supported by Beijing Municipal Commission of Education under the municipal government of Beijing under the Program "Research on reinforcement and stability of nitrogen removal performance in wastewater treatment based on the new landmark conditions" (Z161100004516015).

\section{References}

[1] Strous M, Heijnen J J, Kuenen J G and Jetten M S M 1998 The sequencing batch reactor as a powerful tool for the study of slowly growing anaerobic ammonium-oxidizing microorganisms Appl. Microbiol. Biot. 50 (5) 589-96.

[2] Kartal B, Kuenen J G and Loosdrecht M C M V 2010 Sewage Treatment with anammox Science 328 (5979) 702-3.

[3] Tang C J, Zheng P, Wang C H, Qaisa M, Zhang J J, Chen X G, Zhang L and Chen J W 2011 Performance of high-loaded ANAMMOX UASB reactors containing granular sludge Water Res. 45 (1) 135-44.

[4] Lin X and Wang Y 2017 Microstructure of anammox granules and mechanisms endowing their intensity revealed by microscopic inspection and rheometry Water Res. 120 22-31.

[5] Tsushima I, Ogasawara Y, Kindaichi T, Satoh H and Okabe S 2007 Development of high rate anaerobic ammonium-oxidizing (anammox) biofilm reactors Water Res. 41 (8) 1623-34. 
[6] Laureni M, Weissbrodt D G, Szivák I, Robin O, Nielsen J L, Morgenroth E and Joss A 2015 Activity and growth of anammox biomass on aerobically pre-treated municipal wastewater Water Res. 411 (80) 325336.

[7] Tang C J, Duan C S, Yu C, Song Y X, Chai L Y, Xiao R, Wei Z and Min X B 2017 Removal of nitrogen from wastewaters by anaerobic ammonium oxidation (ANAMMOX) using granules in upflow reactors Environ. Chem. Lett. 15 (2) 311-28.

[8] Jiang C K, Tang X, Tan H, Feng F, Xu Z M, Mahmood Q, Zeng W, Min X B and Tang C J 2019 J. Effect of scrubbing by $\mathrm{NaClO}$ backwashing on membrane fouling in anammox MBR Sci. Total Environ. 670 149-57.

[9] Hsia T H, Feng Y J, Ho C M, Chou W P and Tseng S K 2008 PVA-alginate immobilized cells for anaerobic ammonium oxidation (anammox) process J. Ind. Microbiol. Biot. 35 (7) 721.

[10] Zhu G L, Hu Y Y and Wang Q R 2009 Nitrogen removal performance of anaerobic ammonia oxidation co-culture immobilized in different gel carriers Water Sci. Technol. 59 (12) 2379.

[11] Bae H, Choi M, Chung Y C, Lee S and Yoo Y J 2017 Core-shell structured poly (vinyl alcohol)/sodium alginate bead for single-stage autotrophic nitrogen removal Chem. Eng. J. 322 408-16.

[12] Chen K C and Houng J Y 2008 Cell immobilization with phosphorylated polyvinyl alcohol (PVA) Gel. Immobil. Enzyme. Cell 207-16.

[13] Zhang L and Okabe S 2017 Rapid cultivation of free-living planktonic anammox cells Water Res 127.

[14] Wang X T, Yang H, Su Y, Liu X Y and Wang J W 2021 Characteristics of anammox granular sludge using color differentiation, and nitrogen removal performance of its immobilized fillers based on microbial succession Bioresour. Technol. 125188.

[15] Guan Q and Yang H 2017 Determination of diffusion coefficient of PVA gel and optimization of its mass transfer performance Chinese Journal of Environmental Engineering 11 1375-82.

[16] Strous M, Van Gerven E, Kuenen J G and Jetten M 1997 Effects of aerobic and microaerobic conditions on anaerobic ammonium-oxidizing (anammox) sludge Appl. Environ. Microbiol. 63 (6).

[17] APHA (American Public Health Association) 2005 Standard Methods for the Examination of Water and Wastewater 21th ed. (Washington, DC: American Public Health Association).

[18] Wang X T, Yang H, Liu X Y and Su Y 2019 Effects of biomass and environmental factors on nitrogen removal performance and community structure of an anammox immobilized filler Sci. Total Environ. $\mathbf{7 1 0}$ 135258.

[19] Egli K, Fanger U, Alvarez P J J, Siegrist H, Meer J R V D and Zehnder A J B 2001 Enrichment and characterization of an anammox bacterium from a rotating biological contactor treating ammonium-rich leachate Archives of Microbiology 175 (3) 198-207.

[20] Ali M, Oshiki M, Rathnayake L, Ishii S, Satoh H and Okabe S 2015 Rapid and successful start-up of anammox process by immobilizing the minimal quantity of biomass in PVA-SA gel beads Water Res. 79 147-57.

[21] Tao M X, Wang M, Hu X J, Shang H Y and Yang H 2015 Start-up of ANAMMOX bioreactor with ANAMMOX bacteria immobilized in partial granular activated carbon Chinese Journal of Environmental Engineering 9 (8) 3835-40.

[22] Chen G H, Li J, Deng H L, Zhang Y Z, Zhao B H and Zheng Z M 2015 Performance and kinetic Characteristics of immobilized granules on start-up of anammox bioreactor CIESC Journal 66 (4) 145966.

[23] Cao S B, Du R, Li B K, Ren N Q and Peng Y Z 2016 High-throughput profiling of microbial community structures in an ANAMMOX-UASB reactor treating high-strength wastewater Applied Microbiology and Biotechnology 100 (14) 6457-67.

[24] Yue H, Zhang Y Y, He Y L, Wei G H and Shu D T 2019 Keystone taxa regulate microbial assemblage patterns and functional traits of different microbial aggregates in simultaneous anammox and denitrification (SAD) systems Bioresour. Technol. 121778. 